\title{
Efficacy and safety of ethanolic Curcuma longa extract as a treatment for sand tampan ticks in a rabbit model
}

\author{
Sobhy Abdel-Shafy ${ }^{1} \mathbb{D}$, Abdullah D. Alanazi ${ }^{\mathbb{D}}$, Hanan S. M. Gabr ${ }^{3}$, Ahmad M. Allam ${ }^{1}$ D, Hala A. A. Abou-Zeina ${ }^{1}$,
} Ragab A. Masoud ${ }^{4}$ D, Doaa E. Soliman ${ }^{5}$ and Mohammad Yahya Alshahrani ${ }^{6}$

1. Department of Parasitology and Animal Diseases, Veterinary Research Division, National Research Centre, Dokki, Giza, Egypt; 2. Department of Biological Science, Faculty of Science and Humanities, Shaqra University, P.O. Box 1040, Ad-Dawadimi 11911, Saudi Arabia; 3. Department of Zoology and Agricultural Nematology, Faculty of Agriculture, Cairo University, Giza, Egypt; 4. Department of Tanning Materials and Leather Technology, Chemical Industry Research Division, National Research Centre, Dokki, Giza, Egypt; 5. Department of Entomology, Faculty of Science, Ain Shams University, Cairo, Egypt; 6. Department of Clinical Laboratory Sciences, College of Applied Medical Sciences, King Khalid University, P.O. Box 61413, Abha, 9088, Saudi Arabia.

Corresponding author: Sobhy Abdel-Shafy, e-mail: aasobhy@yahoo.com

Co-authors: ADA: aalanazi@su.edu.sa, HSMG: hanangabr@agr.cu.edu.eg, AMA: ahmdallam@gmail.com, HAAA: hala_zeina60@yahoo.com, RAM: ragab17@gmail.com, DES: doaasol@yahoo.com, MYA: moyahya@kku.edu.sa Received: 27-12-2019, Accepted: 03-04-2020, Published online: 29-04-2020

doi: www.doi.org/10.14202/vetworld.2020.812-820 How to cite this article: Abdel-Shafy S, Alanazi AD, Gabr HSM, Allam AM, Abou-Zeina HAA, Masoud RA, Soliman DE, Alshahrani MY (2020) Efficacy and safety of ethanolic Curcuma longa extract as a treatment for sand tampan ticks in a rabbit model, Veterinary World, 13(4): 812-820.

\begin{abstract}
Background and Aim: The soft tick Ornithodoros savignyi is distributed throughout Africa, including Egypt. It primarily attacks camels, cattle, donkeys, and cows; and rarely affects humans. This study evaluated the acaricidal efficacy of ethanolic Curcuma longa extract (Turmeric) on the second nymphs of $O$. savignyi and then investigated the safety of this herb in rabbits.

Materials and Methods: The nymphs were immersed in 10,5,2.5, 1.25, and $0.625 \mathrm{mg} / \mathrm{ml}$ ethanolic C. longa extract. An additional group was immersed in ethanol as a control. On the $1^{\text {st }}, 7^{\text {th }}$, and $15^{\text {th }}$-day post-treatment, the mortality percentages, $\mathrm{LC}_{50}$, and $\mathrm{LC}_{95}$ were calculated. The ticks exposed to $10 \mathrm{mg} / \mathrm{ml}$ ethanol $C$. longa extract were investigated by scanning electron microscopy (SEM). Three male New Zealand White rabbits were orally administered $2 \mathrm{ml}$ (two doses) of $10 \mathrm{mg} / \mathrm{ml}$ ethanolic $C$. longa extract, and another three rabbits were orally given two doses of $2 \mathrm{ml}$ of absolute ethanol as a negative control. Histopathological examination of the kidney and liver hematology and the kidney and liver function was performed. Chemical analysis of the extract was determined by gas chromatography-mass spectrometry (GC-MS).

Results: The $\mathrm{LC}_{50}$ and $\mathrm{LC}_{95}$ were 1.31 and $15.07,1.07$ and 8.56 , and 0.81 and $6.97 \mathrm{mg} / \mathrm{ml}$ on the $1^{\text {st }}, 7^{\text {th }}$, and $15^{\text {th }}$ day, respectively. SEM revealed that mamillae and spots on the surfaces of the treated ticks were not discriminating except for some clefts on the surfaces. The histological examination, blood profile, and biochemical analyses revealed no significant differences between the treated and untreated rabbits $(\mathrm{p}>0.05)$. GC/MS analysis revealed 50 compounds, and curcumene and tumerone were found to be the major constituents of this ethanolic extract.
\end{abstract}

Conclusion: The ethanolic $C$. longa extract produced a strong acaricidal effect on the second nymph of $O$. savignyi, and it was safe to use in rabbits.

Keywords: histopathology, scanning electron microscopy, soft ticks, tick control, turmeric.

\section{Introduction}

Ornithodoros savignyi is distributed throughout Africa, including Egypt. It primarily attacks animals (camels, cattle, donkeys, and cows); however, rare cases have been found in humans [1,2]. Bites from these ticks cause severe biting stress, paralysis, and toxicosis $[1,3]$. O. savignyi is a vector and a causative agent of many diseases such as Borrelia spp. [4,5], Alkhurma hemorrhagic fever virus [6], and Bluetongue virus 8 [7]. Medicinal plants are excellent

Copyright: Abdel-Shafy, et al. Open Access. This article is distributed under the terms of the Creative Commons Attribution 4.0 International License (http://creativecommons.org/licenses/ by/4.0/), which permits unrestricted use, distribution, and reproduction in any medium, provided you give appropriate credit to the original author(s) and the source, provide a link to the Creative Commons license, and indicate if changes were made. The Creative Commons Public Domain Dedication waiver (http:// creativecommons.org/publicdomain/zero/1.0/) applies to the data made available in this article, unless otherwise stated. alternatives to synthetic pesticides as they are ecofriendly, safe for humans and non-target organisms, rapidly biodegradable, and minimally resistant to pests $[8,9]$. Recent studies have evaluated the effectiveness of crude extracts and essential oils from plants against various tick species [10-12]. Moreover, some commercial acaricides are prepared from plants; and neem and myrrh have exhibited lethal effects against ticks $[13,14]$.

Curcuma longa L. is botanically related to the Zingiberaceae family. Turmeric is a spice obtained from the root of $C$. longa that has multiple medicinal properties, including antibacterial, antimalarial, antiviral, anti-aging, anticancer, anti-Alzheimer's disease, antifungal, antioxidant, and anti-inflammatory, as well as efficacy as a snail repellent [8,15-21]. An ethanolic C. longa extract exhibited efficacy against the Toxoplasma 
gondii tachyzoites in mice [22]. Turmeric possesses well-known insecticidal and repellent properties against insect pests. The ethanolic extracts of three Curcuma species Curcuma aeruginosa, Curcuma aromatica, and Curcuma xanthorrhiza have displayed mosquito repellent activity [23]. Two compounds isolated from the ethanolic $C$. longa extract ar-turmerone and 8-hydroxyl-ar-turmerone have both exhibited larvicidal effects against the fourth instar larvae of Culex pipiens [24].

However, the effect of $C$. longa extract on ticks has not previously been studied. Therefore, this research evaluated the acaricidal efficacy of the ethanolic $C$. longa extract on the soft tick $O$. savignyi and investigated the safety of this herb in rabbits used as an animal model.

\section{Materials and Methods}

\section{Ethical approval}

This study was approved to the ethical standards used in this study and the relevant national and institutional guidelines on the care and use of laboratory animals were approved by the Medical and Veterinary Research Ethics Committee (No, 19014) at the National Research Centre in Egypt.

\section{Tick collection}

Adult and nymph stage $O$. savignyi ticks were collected from the grounds of the camel market in Shalateen, Egypt $\left(23^{\circ} 7^{\prime} 54^{\prime \prime} \mathrm{N}, 35^{\circ} 35^{\prime} 8^{\prime \prime} \mathrm{E}\right)$, during September 2018 (Figure-1). Live ticks were taken to the laboratory and identified morphologically using the taxonomic key of Walker et al. [1]. The second-instar nymphs were used to evaluate the effects of the ethanolic C. longa extract.

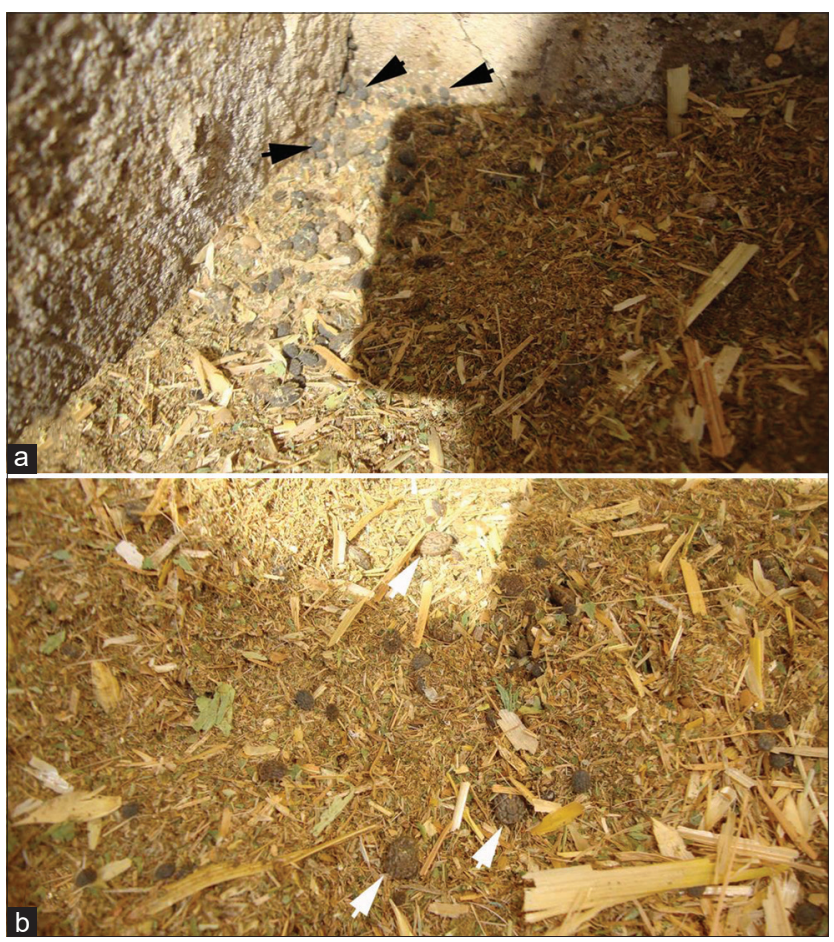

Figure-1: The soft tick Ornithodoros savignyi on the ground of the camel yard: (a) Nymphs, (b) adults.

\section{Preparation of the ethanolic $C$. longa extract}

Dried rhizomes of $C$. longa were purchased from a local market in Cairo, Egypt. The dried powder was treated with $95 \%$ ethanol and evaporated under reduced pressure using a rotatory evaporator. The ethanolic extract was prepared using the dried C. longa rhizomes following the method described by Wang and Waller [25]. Briefly, the powder was macerated several times at room temperature for 1 week with $95 \%$ ethyl alcohol before filtering using Whatman no. 1 filter paper. The solvent was removed under reduced pressure at $40^{\circ} \mathrm{C}$ using a rotary evaporator until a thick paste was formed. This thick paste was considered a concentrated extract. Extracts were stored at $4^{\circ} \mathrm{C}$ in a refrigerator until use. The different concentrations of the extract were generated by mixing the appropriate volumes of ethanol.

The toxicity of the ethanolic $C$. longa extract on ticks

Concentrations of the ethanolic $C$. longa extract were prepared at $10,5,2.5,1.25$, and $0.625 \mathrm{mg} / \mathrm{ml}$. A total of 360 O. savignyi second nymphs were used during testing; 60 nymphs for each concentration and an additional 60 nymphs as a control group. Each treatment group included three replicates containing 20 nymphs per replicate. The control group contained the same number of ticks, and each was immersed in ethanol as the control treatment. Treatment consisted of immersion of the ticks in the specified extract for $1 \mathrm{~min}$ before being transferred to the filter paper to absorb the excess extract. Once dry, the nymphs were placed into plastic tubes. These tubes were covered with a piece of cloth secured by a rubber band and incubated at $27^{\circ} \mathrm{C}, 75 \%$ relative humidity for 2 weeks. The tick mortality was recorded on the $1^{\text {st }}, 7^{\text {th }}$, and $15^{\text {th }}$ days post-treatment. Images of the dead nymphs (from the treatment groups) and live nymphs (control) were acquired using a stereomicroscope. Several dead nymphs from those exposed to the $10 \mathrm{mg} / \mathrm{ml}$ extract were preserved in $70 \%$ ethanol for imaging with a scanning electron microscope (SEM).

\section{SEM of ticks treated with ethanolic $C$. longa extract}

The nymphs that died as a result of the treatment with $10 \mathrm{mg} / \mathrm{ml}$ ethanol C. longa extract were preserved in $10 \%$ ethanol on the $1^{\text {st }}$-day post-treatment, and several live nymphs from the control group were preserved in $70 \%$ ethanol for comparison. The nymphs were prepared for SEM according to the method described by Abdel-Shafy [26]. Briefly, the nymphs previously preserved in ethanol were cleaned using a water-glycerol- $\mathrm{KCl}$ solution, fixed in glutaraldehyde, immersed in a series of graded alcohol, glued by their dorsal and ventral surfaces to the SEM stub, dried with a dryer (Blazer Union, F1-9496 Blazer/ Fürstentun Liechtenstein), mounted on SEM stubs, coated with gold using an S15OA Sputter Coater, and examined by SEM.

The safety of the ethanolic $C$. longa extract in rabbits Six male New Zealand White rabbits weighing approximately $2.0 \mathrm{~kg}$ were used for the in vivo 
evaluation of the ethanolic turmeric extract. Animals were divided randomly into two groups. The test group ( $\mathrm{n}=3$ ) received $2 \mathrm{ml}$ of an oral dose of $10 \mathrm{mg} / \mathrm{ml}$ ethanolic C. longa extract. The second group $(\mathrm{n}=3)$ was kept as a negative control where the rabbits were orally administered $2 \mathrm{ml}$ of absolute ethanol. All rabbits were monitored for 1 week and received the treatment twice during this time with a 3-day interval between the two doses. At the end of the experiment, the rabbits were euthanized by carbon dioxide gas asphyxiation with extra confirmation of death by head dislocation, according to the American Veterinary Medical Association guidelines for the euthanasia of animals [27]. The livers and kidneys were retrieved and fixed in $10 \%$ neutral buffered formalin for further pathological examination. Paraffin tissue sections at 4-6 $\mu \mathrm{m}$ thickness were prepared and stained with hematoxylin and eosin for histopathological examination. Histological slides were examined by light microscopy [28]. Blood samples were collected from all rabbits at the end of the experiment. A hemogram test was conducted according to the method described by Weiss and Wardrop [29]. The activities of aspartate aminotransferase and alanine aminotransferase were determined according to the procedure of Reitman and Frankel [30]. Serum urea and creatinine were determined according to the methods of Patton and Crouch [31], and Houot [32], respectively.

\section{Gas chromatography (GC)/mass spectrometry (MS) analysis}

GC (Agilent Technologies 7890A, CA, USA) interfaced with a mass-selective detector (Agilent 7000 Triple Quad, CA, USA) and the Agilent HP-5ms capillary column $(30 \mathrm{~m} \times 0.25 \mathrm{~mm}$ ID, $0.25 \mu \mathrm{m}$ film thickness) were used for analysis. The flow rate was $1 \mathrm{~mL} / \mathrm{min}$ using helium $(\mathrm{He})$ as the carrier. The injector and detector temperatures were $200^{\circ} \mathrm{C}$ and $250^{\circ} \mathrm{C}$, respectively. The acquisition mass range was 50-600. The formulae of the components were identified by comparing the mass spectra and RT information recorded with those of the NIST and WILEY library.

\section{Statistical analysis}

A one-way analysis of variance was used for the statistical analysis between the tick mortality percentages using the $F$ and Tukey's tests at $p<0.05$. The statistical analysis between the treated and control rabbits for each blood parameter was performed using a Student's t-test. All statistical analyses were conducted using SPSS Version 14 (IBM Inc., NY, USA).

\section{Results}

The toxicity of the ethanolic $C$. longa extract on the O. savignyi second nymphs

The primary readout for this experiment included the mortality percentages of the $O$. savignyi nymphs treated with $0.625,1.25,2.5,5$, and $10 \mathrm{mg} / \mathrm{ml}$ ethanolic $C$. longa extract on the $1^{\text {st }}, 7^{\text {th }}$, and $15^{\text {th }}$ days post-treatment (Table-1). Statistical analysis revealed significant differences between the mortalities $(p<0.001)$ recorded for all of the concentrations at each time point post-treatment. The highest mortalities were recorded at concentrations of $2.5-10 \mathrm{mg} / \mathrm{ml}$ during the 2 weeks post-treatment. However, the control group exhibited little mortalities (3.3-6.7\%). All treatment concentrations and the control group experienced a non-significant increase in mortality throughout the days of post-treatment ( $\mathrm{p}>0.05$ ). The $\mathrm{LC}_{50}$ and $\mathrm{LC}_{95}$ slightly decreased over the days of post-treatment 1.31 and 15.07, 1.07 and 8.56, and 0.81 and $6.97 \mathrm{mg} / \mathrm{ml}$ on the $1^{\text {st }}, 7^{\text {th }}$, and $15^{\text {th }}$ day, respectively (Table-2). There were changes evident in the O. savignyi nymphs treated with $10 \mathrm{mg} / \mathrm{ml}$ of the ethanolic $C$. longa extract compared to that of the controls treated with ethanol. The size and color of the nymphs in the control group remained normal, a dark brown with creamy white legs (Figure-2a and b). In contrast, the treated nymphs were dark red, with swollen bodies, and pink legs (Figure-2c and d).

\section{SEM analysis of the 0 . savignyi second nymphs}

Untreated nymphs exhibited distinctive vertical and horizontal grooves with spots that were visible inside, as well as mammillae all over the dorsal surface (Figure-3a and b). A mammilla is a broad protuberance with one or two holes at the apex (Figure-3c). A spot is a small tapering protuberance without any holes on the apex (Figure-3d). However, the dorsal surface of the treated nymphs exhibited shallow vertical and horizontal grooves (Figure-4a), and the mammillae appeared to be adhering to each other (Figure-4b and c). Spots on the treated nymphs were an undiscriminating shape (Figure-4d). The ventral surface of the untreated nymphs exhibited wrinkled integument, mammillae, and spots scattered between mammillae throughout the ventral surface (Figure-5a-d), whereas the ventral surface of a treated nymph showed indistinctive mammillae and spots (Figure-6a-d).

\section{The safety of the ethanolic $C$. longa extract in rabbits}

No major abnormalities were seen in the kidneys of either the negative controls or the treated groups of rabbits (Figure-7a and b). The histological examination

Table-1: Mortality percentages (Mean \pm SE) of O. savignyi second nymphs treated with ethanolic $C$. longa extract.

\begin{tabular}{lccc}
\hline \multirow{2}{*}{$\begin{array}{l}\text { Concentration } \\
\mathbf{m g} / \mathbf{m l})\end{array}$} & \multicolumn{3}{c}{ Day post-treatment } \\
\cline { 2 - 4 } & $\mathbf{1}^{\text {st }}$ & $\mathbf{7}^{\text {th }}$ & $\mathbf{1 5}^{\text {th }}$ \\
\hline 10 & $93.3 \pm 6.7^{\mathrm{a}}$ & $96.7 \pm 3.3^{\mathrm{ab}}$ & $96.7 \pm 3.3^{\mathrm{a}}$ \\
5 & $76.7 \pm 8.8^{\mathrm{ab}}$ & $90.0 \pm 0.0^{\mathrm{ab}}$ & $93.3 \pm 3.3^{\mathrm{a}}$ \\
2.5 & $73.3 \pm 12.0^{\mathrm{ab}}$ & $73.3 \pm 12.0^{\mathrm{abc}}$ & $83.3 \pm 12.0^{\mathrm{ab}}$ \\
1.25 & $50.0 \pm 5.8^{\mathrm{bc}}$ & $56.7 \pm 8.8^{\mathrm{bc}}$ & $63.3 \pm 3.3^{\mathrm{ab}}$ \\
0.625 & $30.0 \pm 10.0^{\mathrm{cd}}$ & $36.7 \pm 16.7^{\mathrm{cd}}$ & $46.7 \pm 14.5^{\mathrm{b}}$ \\
Control & $3.3 \pm 3.3^{\mathrm{d}}$ & $3.3 \pm 3.3^{\mathrm{d}}$ & $6.7 \pm 3.3^{\mathrm{c}}$ \\
Butex & $93.3 \pm 6.7^{\mathrm{a}}$ & $100 \pm 0.0^{\mathrm{a}}$ & - \\
F value & 17.642 & 16.972 & 17.650 \\
Probability $(\mathrm{p})$ & $<0.001$ & $<0.001$ & $<0.001$ \\
\hline
\end{tabular}

Small letters indicate to the significant difference between means using Tukey test at $\mathrm{p}<0.05$.

O. savignyi=Ornithodoros savignyi, C. longa=Curcuma longa 
Table-2: $\mathrm{LC}_{50}$ and $\mathrm{LC}_{95}$ values with their confidence limits for $O$. savignyi second nymphs treated with the ethanolic C. longa extract.

\begin{tabular}{|c|c|c|c|c|c|c|c|}
\hline \multirow{3}{*}{$\begin{array}{l}\text { Day post } \\
\text { treatment }\end{array}$} & \multirow[t]{3}{*}{$\mathrm{LC}_{50}(\mathrm{mg} / \mathrm{ml})$} & \multirow[t]{3}{*}{$\mathrm{LC}_{95}(\mathrm{mg} / \mathrm{ml})$} & \multicolumn{4}{|c|}{ Confidence limits } & \multirow[t]{3}{*}{ Slope \pm SE } \\
\hline & & & \multicolumn{2}{|c|}{$\mathrm{LC}_{50}(\mathrm{mg} / \mathrm{ml})$} & \multicolumn{2}{|c|}{$\mathrm{LC}_{95}(\mathrm{mg} / \mathrm{ml})$} & \\
\hline & & & Lower & Upper & Lower & Upper & \\
\hline$\overline{1^{\text {st }}}$ & 1.31 & 15.07 & 1.05 & 1.58 & 10.44 & 25.61 & $1.55 \pm 0.16$ \\
\hline $7^{\text {th }}$ & 1.07 & 8.56 & 0.86 & 1.27 & 6.42 & 12.79 & $1.82 \pm 0.17$ \\
\hline $15^{\text {th }}$ & 0.81 & 6.97 & 0.62 & 0.99 & 5.22 & 10.55 & $1.76 \pm 0.18$ \\
\hline
\end{tabular}

O. savignyi=Ornithodoros savignyi, C. longa=Curcuma longa

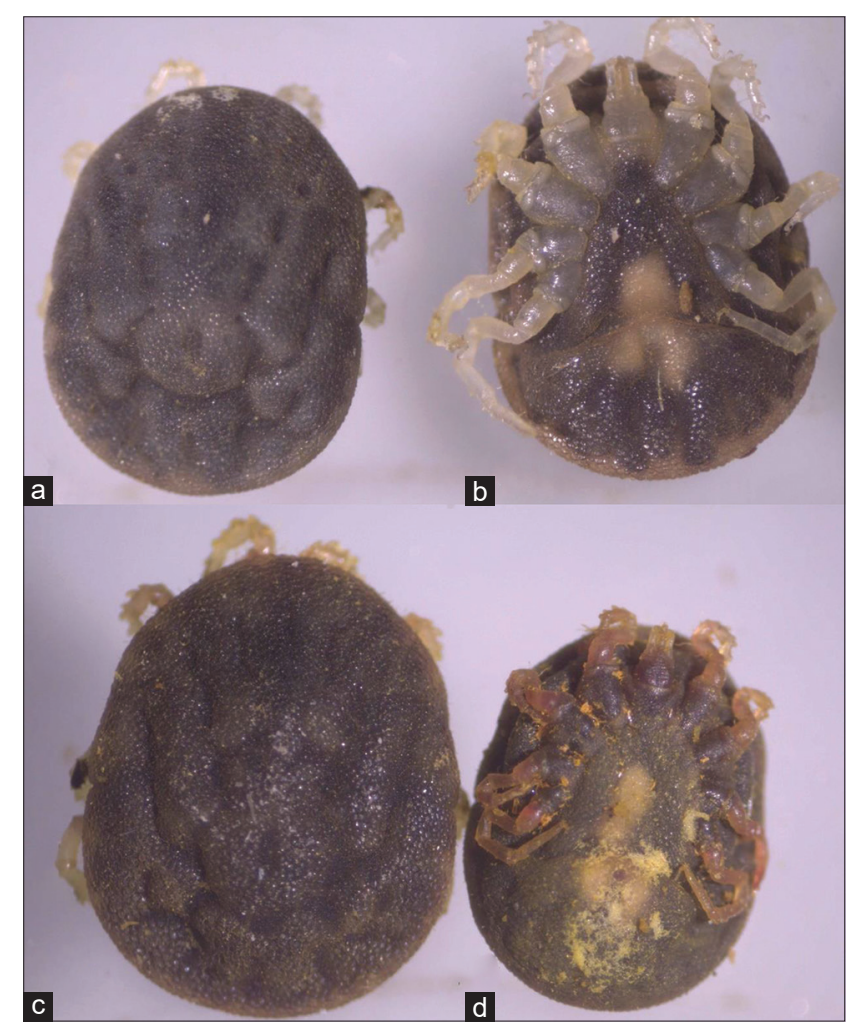

Figure-2: The Ornithodoros savignyi second nymphs treated with $10 \mathrm{mg} / \mathrm{ml}$ ethanolic Curcuma longa extract: (a) Dorsal view of nymph exposed to the ethanol only as a control, (b) ventral view of nymph exposed to the ethanol only as a control, (c) dorsal view of nymph immersed in the ethanolic $C$. longa extract, (d) ventral view of nymph immersed in the ethanolic $C$. longa extract.

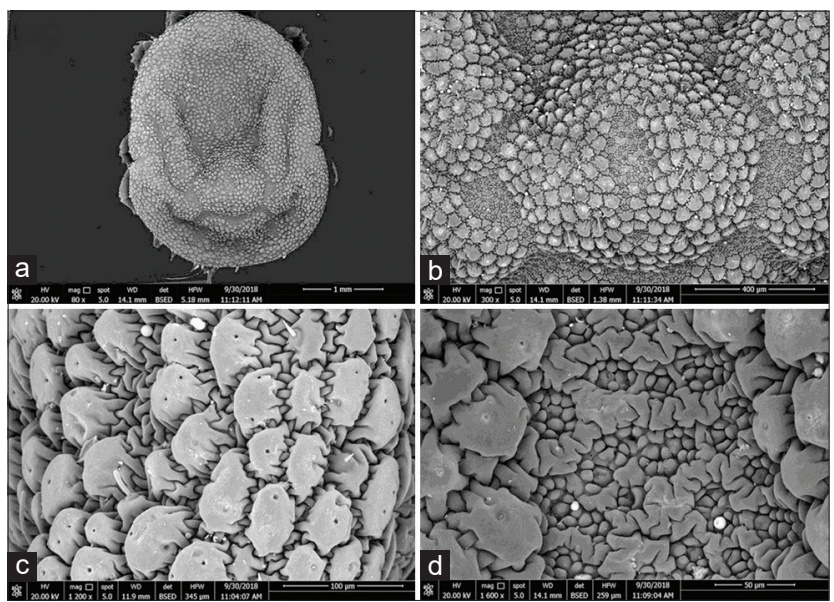

Figure-3: Dorsal view of untreated Ornithodoros savignyi second nymph showing: (a) Depressing areas and well distinctive vertical and horizontal grooves, (b) mamillae and spots together, (c) mamilae with one or two holes on their apex, (d) small spots without any holes on their apex.

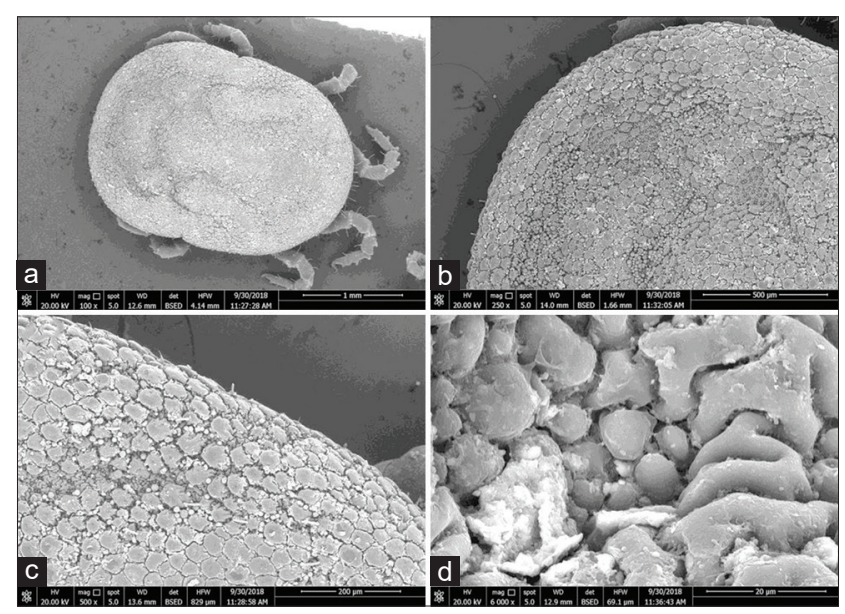

Figure-4: Dorsal view of treated Ornithodoros savignyi second nymph by $10 \mathrm{mg} / \mathrm{ml}$ ethanolic Curcuma longa extract showing: (a) Slightly depressing areas and shallow vertical and horizontal grooves, (b) mamillae and spots together, (c) mamilae adhere to each other, (d) undiscriminating spots.
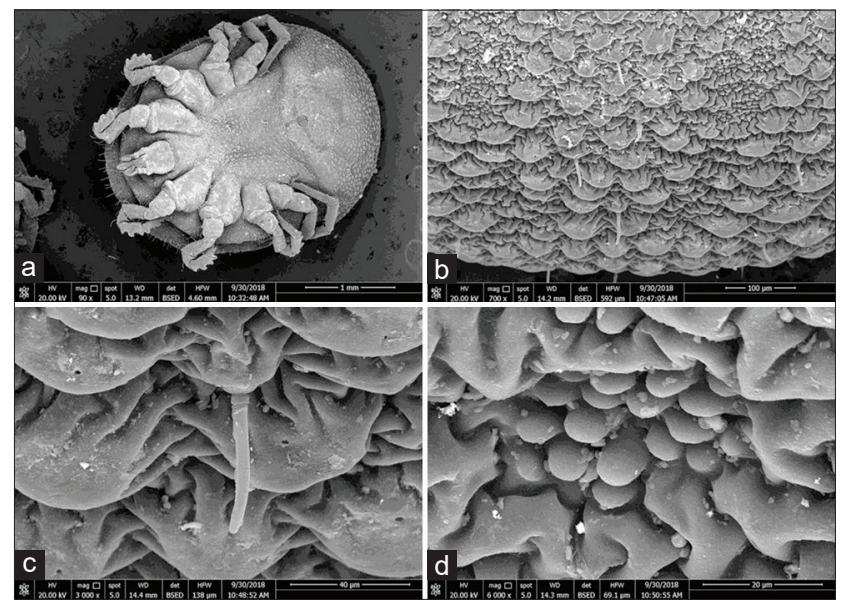

Figure-5: Ventral view of untreated Ornithodoros savignyi second nymph showing: (a) Wrinkle integument, mammillae, and spots, (b) mamillae and spots together, (c) mamillae with one hole on their apex, (d) small spots without any holes on their apex.

of the livers from the negative control rabbits showed no pathological abnormalities (Figure-7c). Liver tissue sections of rabbits that ingested ethanolic C. longa extract showed dilation, congestion of the portal, and central veins, areas of vacuolar degeneration, and congestion of the central venules, sinusoids, and portal triad (Figure-7d). The blood profile, kidney function, and liver function were within the normal range in 


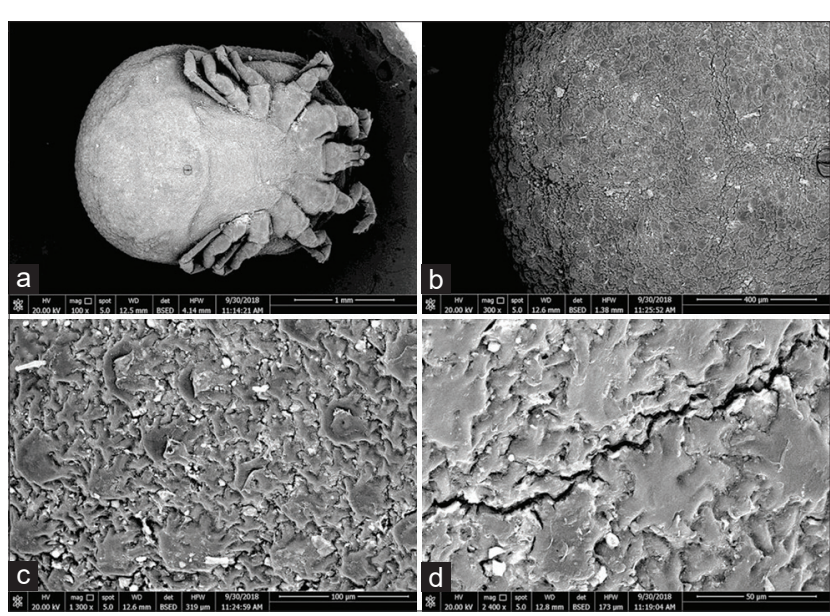

Figure-6: Ventral view of treated Ornithodoros savignyi second nymph by $10 \mathrm{mg} / \mathrm{ml}$ ethanolic Curcuma longa extract showing: (a) Indistinctive mammillae and spots, (b) diffused mamillae and spots to form flat surface, (c) mamillae merge each other and spots to form flat surface, (d) long cleft on the surface.

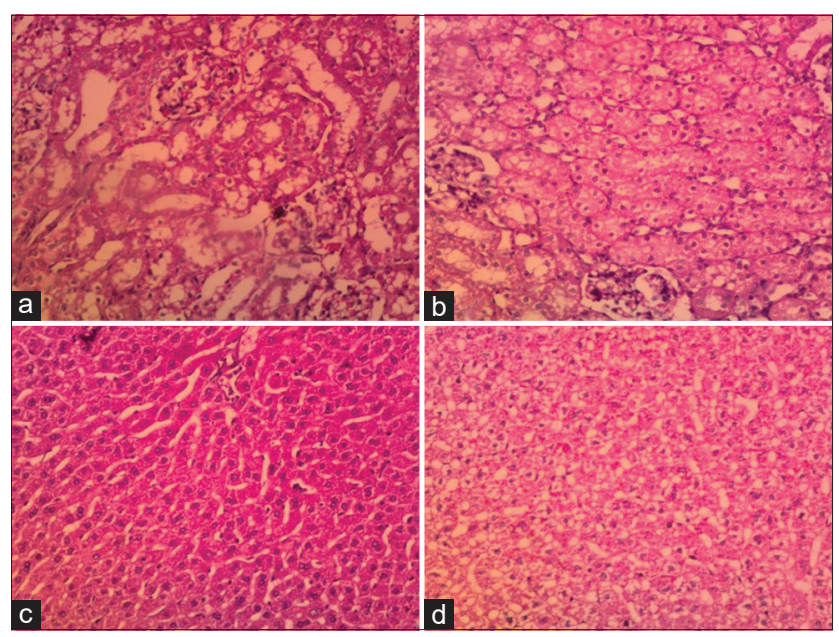

Figure-7: Cross sections in the kidney and liver of the rabbits that orally took $2 \mathrm{ml}$ of $10 \mathrm{mg} / \mathrm{ml}$ ethanolic Curcuma longa extract in the treated group and $2 \mathrm{ml}$ of absolute ethanol in the negative control group (Hematoxylin and eosin; $\times 200$ ): (a) Negative control of the kidney showed the normal architecture. (b) The kidney of the rabbit administered $C$. longa extract. (c) Negative control of the liver showed normal architecture with few degenerated areas. (d) The liver of the rabbit administered $C$. longa extract showing moderate reversible liver cell damage in the form of degeneration and congestion.

both the control and treated rabbits with non-statistically significant differences ( $\mathrm{p}>0.05$ ) (Table-3).

\section{Phytochemical analyses of the ethanolic $C$. Ionga extract}

GC-MS analysis of the ethanol extract of C. longa identified the major chemical constituents based on the peak retention time (Rt) and percentage area. A total of 50 compounds were identified, and the most abundant were as follows (the percentage of abundance is stated in brackets) $\beta$-curcumene (30.71), tumerone (7.14), germacone (6.08), $\beta$-cedrene (4.59), cedr-8-ene (3.87), $\beta$-cubebene (3.34), cis-sesquisabinene hydrate (2.51), p-Cymen-2-ol (2.49), $\beta$-himachalene (2.26), Cis-p-mentha-2,8-diene-1-ol (2.1),
Table-3: Blood profile and liver and kidney functions of rabbits ingested 2 times of $10 \mathrm{mg} / \mathrm{ml}$ ethanolic $C$. longa extract.

\begin{tabular}{lcc}
\hline Parameter & Treated & Control \\
\hline RBCs & $5.52 \pm 0.23$ & $5.86 \pm 0.01$ \\
$\mathrm{Hb}$ & $12.90 \pm 0.17$ & $13.00 \pm 0.13$ \\
$\mathrm{HCT}$ & $36.95 \pm 0.03$ & $37.95 \pm 0.38$ \\
$\mathrm{MCV}$ & $61.55 \pm 0.49$ & $61.65 \pm 0.95$ \\
$\mathrm{MCH}$ & $21.40 \pm 0.46$ & $22.05 \pm 0.23$ \\
MCHC & $34.70 \pm 0.40$ & $34.20 \pm 0.06$ \\
Platelets & $452.00 \pm 17.90$ & $357.50 \pm 12.41$ \\
WBCs & $6.35 \pm 0.20$ & $6.40 \pm 0.06$ \\
Urea & $26.20 \pm 0.64$ & $20.15 \pm 1.01$ \\
Creatinine & $1.15 \pm 0.03$ & $0.95 \pm 0.03$ \\
ALT & $110.00 \pm 9.81$ & $95.50 \pm 1.44$ \\
AST & $58.95 \pm 2.34$ & $41.50 \pm 2.60$ \\
\hline
\end{tabular}

RBCs=Red blood corpuscular counts, $\mathrm{Hb}=$ Hemoglobin, $\mathrm{HCT}=$ Hematocrit. $\mathrm{MCV}=$ Mean corpuscular volume. $\mathrm{MCH}=$ Mean corpuscular hemoglobin. $\mathrm{MCHC}=$ Mean corpuscular hemoglobin concentration, WBCs $=$ White blood cell counts, ALT=Alanine aminotransferase. $A S T=$ Aspartate aminotransferase, $O$. savignyi=Ornithodoros savignyi, C. longa = Curcuma longa

farnesol (2.1), 7,3'-Dimethyoy-3-hydroxyflavone (2.09), and pinane (2.06) (Table-4 and Figure-8).

\section{Discussion}

Alcohols are solvents that have demonstrated superior extractive power for almost all-natural substances of low molecular weight, such as alkaloids, saponins, and flavonoids [33]. The ethanolic extracts from the rhizome of $C$. longa $\mathrm{L}$. possessed a wide variety of biological activities related to the treatment and prevention of various clinical conditions [34]. The $C$. longa rhizome extract was reportedly a more potent antimicrobial agent than the leaf extract [18], and higher concentrations of curcumin and antioxidant activity were obtained when ethanol was used as the solvent for extraction [17]. Therefore, this study evaluated the effects of the crude ethanolic extract of $C$. longa $\mathrm{L}$. against the second nymphs of the soft tick $O$. savignyi, which was found in large numbers on the grounds of a local camel yard in Egypt. The safety of this extract in rabbits was also evaluated. The C. longa L. rhizome was selected for extraction and evaluation against this tick species for three reasons: (1) It is available in the local market in a powder form for a low price, (2) the previous studies found that different $C$. longa $\mathrm{L}$. derived materials exhibited strong insecticidal activity on various insect pests such mosquitoes, and (3) no previous studies had evaluated the effects of $C$. longa L. extract on this tick species.

In this study, it was found that the O. savignyi second nymphs were highly susceptible to the ethanolic C. longa extract as $2.5-10 \mathrm{mg} / \mathrm{ml}$ of the extract caused $73.3-96.7 \%$ mortality in the nymphs after 1 week of treatment. There were non-statistically significant differences $(p>0.05)$ between the mortality range recorded with the extract and the mortality range of the reference acaricide (93.3 and 100\%). The calculated 
Table-4: GC-MS of ethanol extract of C. longa using library.

\begin{tabular}{|c|c|c|c|}
\hline No. & Rt (min) & Name of active compounds & $\%$ peak area \\
\hline 1 & 3.5 & D-2,3-Butane diol & 1.21 \\
\hline 2 & 5.7 & o-cymene & 0.34 \\
\hline 3 & 6.73 & Terpinolene & 0.64 \\
\hline 4 & 7.27 & a-thujone & 0.58 \\
\hline 5 & 7.70 & Cis-sabinol & 0.33 \\
\hline 6 & 8.13 & Ciminaldehyde & 0.5 \\
\hline 7 & 8.68 & Thymol & 0.71 \\
\hline 8 & 8.98 & phenol & 0.57 \\
\hline 9 & 9.19 & Dihydrocurcumene & 1.21 \\
\hline 10 & 9.47 & Hemellitol & 0.38 \\
\hline 11 & 9.57 & Cembrene & 0.42 \\
\hline 12 & 9.71 & a-guaiene & 0.96 \\
\hline 13 & 9.82 & Longipinene & 0.37 \\
\hline 14 & 9.91 & $\beta$-bisabolene & 1.75 \\
\hline 15 & 10.04 & Y-gurjunene & 0.54 \\
\hline 16 & 10.28 & $\beta$-Curcumene & 1.08 \\
\hline 17 & 10.41 & Cuparene & 0.47 \\
\hline 18 & 10.45 & Cedr-8-ene & 3.87 \\
\hline 19 & 10541 & $\beta$-Cedrene & 4.59 \\
\hline 20 & 10.72 & Cis-p-mentha-2,8-diene-1-ol & 2.1 \\
\hline 21 & 10.81 & Cis-p-mentha-6,8-diene-2ol & 0.39 \\
\hline 23 & 10.83 & Cis-Lanceol & 1.05 \\
\hline 24 & 10.87 & Geranyl-a-terpinene & 0.64 \\
\hline 25 & 11.08 & $\beta$-Himachalene & 2.26 \\
\hline 26 & 11.19 & Spathulenol & 0.51 \\
\hline 27 & 11.368 & Nopol (terpene) & 1.08 \\
\hline 28 & 11.65 & a-Curcumene & 30.71 \\
\hline 29 & 11.78 & a-bergamotene & 0.55 \\
\hline 30 & 11.81 & Zingiberene & 0.48 \\
\hline 31 & 11.91 & Tumerone & 7.14 \\
\hline 32 & 12.00 & Longiverbenone & 0.66 \\
\hline 33 & 12.102 & Trans-Chrysanthenyl acetate & 1.18 \\
\hline 34 & 12.155 & Caryophyllene oxide & 1.77 \\
\hline 35 & 12.257 & a-terpinene & 0.48 \\
\hline 36 & 12.379 & Germacrone & 6.08 \\
\hline 37 & 12.493 & Elemol & 0.93 \\
\hline 38 & 12.66 & Geranyllinalool & 0.86 \\
\hline 39 & 12.786 & Terpinyl formate & 1.51 \\
\hline 40 & 12.969 & Cis-sesquisabinene hydrate & 2.51 \\
\hline 41 & 13.108 & Corymbolone & 1.51 \\
\hline 42 & 13.365 & a-lonone & 0.59 \\
\hline 43 & 13.495 & p-Cymen-2-ol & 2.49 \\
\hline 44 & 13.678 & $7,3^{\prime}$-Dimethyoy-3-hydroxyflavone & 2.09 \\
\hline 45 & 14.738 & Pinane & 2.05 \\
\hline 46 & 14.774 & Farnesol & 2.1 \\
\hline 47 & 14.86 & $5 \beta, 7 \beta \mathrm{H}, 10$ a-eudesm-11-en-1a-ol & 0.89 \\
\hline 48 & 15.74 & Phytol & 0.38 \\
\hline 49 & 21.456 & Stigmasterol & 0.46 \\
\hline 50 & 22.85 & $\beta$-sitosterol & 0.22 \\
\hline
\end{tabular}

C. longa=Curcuma longa, GC-MS=Gas chromatography-mass spectrometry

$\mathrm{LC}_{50}$ values of the extract used in this research were $1.31,1.07$, and $0.81 \mathrm{mg} / \mathrm{ml}$ on the $1^{\text {st }}, 7^{\text {th }}$, and $15^{\text {th }}$ days, respectively. This indicated that the toxicity of the ethanolic C. longa extract increased over time. Another study [35] had evaluated the effects of C. long $a$ on ticks, using essential oils rather than extract, and their results were similar to the results of the current study [35]. These researchers found that of 11 Brazilian essential oils, C. longa essential oil produced the best results against Rhipicephalus (Boophilus) microplus ticks, with $\mathrm{LC}_{50}$ values of 10.24 and $0.54 \mathrm{mg} / \mathrm{mL}$ against the females and larvae, respectively [35]. Furthermore, the essential oils of Curcuma spp. demonstrated highly larvicidal activity against Aedes aegypti and Anopheles gambiae with $\mathrm{LC}_{50}$ values of 36.30 and $149 \mathrm{ppm}$, respectively [36,37]. In addition, petroleum ether extract from $C$. aromatica showed larvicidal activity against Culex quinquefasciatus at an $\mathrm{LC}_{50}$ value of 11.41 [38]. Moreover, two compounds, ar-turmerone and 8-hydroxyl-ar-turmerone isolated from the ethanolic extracts of the C. longa root, exhibited larvicidal activities against the fourth-instar larvae of $C$. pipiens pallens following $24 \mathrm{~h}$ of treatment; $\mathrm{LC}_{50}$ values were 138.86 and $257.68 \mathrm{ppm}$, respectively [24].

Changes to the morphological features of the ticks were observed on treatment with the ethanolic 


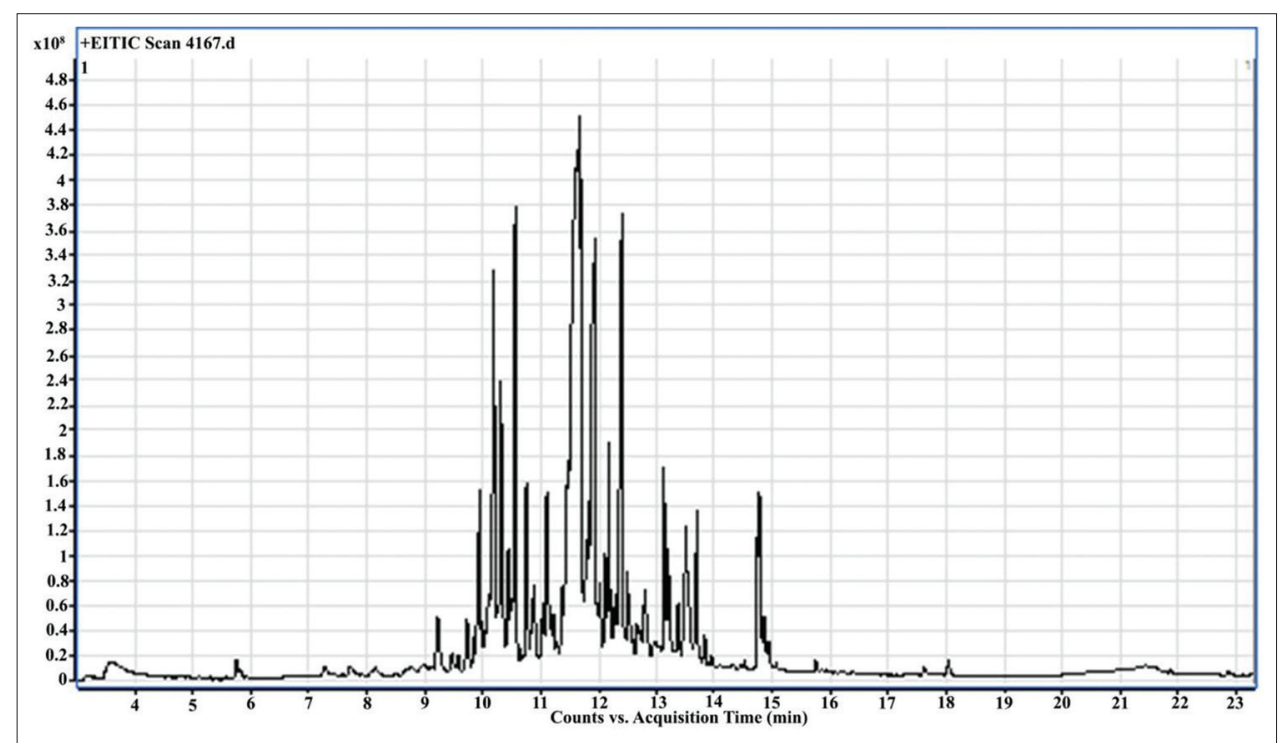

Figure-8: Gas chromatography-mass spectrometry chromatography of the ethanolic Curcuma longa extract.

C. longa extract, cuticles became darker, and the ticks' legs changed from a creamy white color to a pinkish hue. This suggested that the extract could penetrate the tick's cuticle, causing damage to the guts, which spread throughout the tick's body, including the legs. Furthermore, the SEM images revealed additional changes that occurred on the surfaces of the ticks that were exposed to the ethanolic $C$. longa extract. The mammillae of the treated ticks appeared to overlap, the spots on the surface were different, and there were many crevices on the surfaces of treated ticks. These changes might be due to swelling of the tick's body. The ethanolic C. longa extract might cause inhibition of the acetylcholinesterase activity as it contained high levels of polyphenols [39]. Consistent with the effects seen in the present study, Chaaban et al. [40] observed that $C$. longa essential oil caused damage to the tick cuticles, midgut, and brain, and produced a fattening of the body of the third-instar Lucilia cuprina (Diptera: Calliphoridae) larvae.

Two doses of $2 \mathrm{ml}(10 \mathrm{mg} / \mathrm{ml}$ ethanolic) C. longa extract were administered to rabbits with 3 days between doses to assess the safety of the extract in a mammalian system. Biochemical blood parameters were measured for assessment. These parameters were related to health status and considered good indicators of the physiological, pathological, and nutritional status of the animals [41]. The results confirmed the safety of the extract in rabbits. There were no significant changes observed in the kidney function tests or the histological analysis in rabbits that received the extract compared to the control group. Furthermore, there were no significant changes in the blood profile or liver functions between the treated and control rabbits. The results agreed with the findings in the literature [42], in which the authors found no adverse effects on the erythrocytes, leukocytes, or the concentrations of blood constituents. However, slight changes were observed in the livers of the C. longa extract-treated rabbits compared with the control group. Mesa et al. [43] found that oral administration of the C. longa extract reduced susceptibility to the oxidation of erythrocytes and liver microsome membranes. Turmeric's hepatoprotective effect was primarily a result of the antioxidant properties and the ability to reduce the formation of the pro-inflammatory cytokines. Moreover, curcumin administration significantly decreased liver injury [43].

In the present study, the $\mathrm{GC}-\mathrm{MS}$ analyses of the ethanolic C. longa extract revealed 50 compounds, of which the 13 most abundant comprised the majority of the sample. Many of these compounds were major components of essential oils. The natural phytochemicals of $C$. longa have been associated with anticancer, anti-inflammatory, neuroprotective, anti-Alzheimer's, and antioxidant activities. Furthermore, the volatile oil of turmeric has been widely used in cosmetics or health products and possesses antimicrobial, antifungal, and anti-arthritic properties. The natural phytochemicals of $C$. longa are also considered to affect a variety of biological activities $[44,45]$. The two most abundant compounds of the ethanolic $C$. longa extract were curcumene and tumerone, which might be responsible for the acaricidal activity against the second nymphs of $O$. savignyi in the present study. Furthermore, some studies have identified that other compounds isolated from the ethanolic extracts of $C$. longa root have exhibited insecticidal activity against some insects such as mosquitoes. Liu et al. [24] isolated ar-turmerone and 8-hydroxyl-ar-turmerone from the $C$. longa root ethanolic extracts and identified larvicidal activities against the fourth-instar larvae of C. pipiens. Furthermore, Ali et al. [46] discovered that the ethanolic extract of $C$. longa was comprised $15.4 \%$ of ar-turmerone, $6.6 \%$ of bisdesmethoxycurcumin, $6.1 \%$ of desmethoxycurcumin, and $22.6 \%$ of curcumin. 


\section{Conclusion}

The ethanolic curcumene and tumerone were the most abundant constituents identified in the extract. The ethanolic $C$. longa extract elicited a strong acaricidal effect on the second nymphs of the soft tick $O$. savignyi, while no adverse effects were found in the rabbits. Therefore, this extract could be used in pest management applications against ticks found on animals.

\section{Authors' Contributions}

All authors shared in the study plan. SA, HSMG performed the bioassay of the ethanolic $C$. longa extract on the ticks. SA, HSMG, and AMA participated in the administration of the ethanolic $C$. longa extract in the rabbits. SA and DES photograph the ticks by light microscope and scanning electron microscope and analyzed the data. AMA analyzed the blood and performed the cross-sections of the rabbit organs. HAAA and RAM participated in the chemical analyses of the ethanolic $C$. longa extract. SA, AMA, HAAA, RAM, ADA, and MYA shared in writing the manuscript. All authors revised and approved the final manuscript.

\section{Acknowledgments}

This study is a part of project No.11020303, which was financially supported by the National Research Centre, Giza, Egypt.

\section{Competing Interests} interests.

The authors declare that they have no competing

\section{Publisher's Note}

Veterinary World remains neutral with regard to jurisdictional claims in published institutional affiliation.

\section{References}

1. Walker, A.R., Bouattour, A., Camicas, J.L., EstradaPena, A., Horak, I.G., Latif, A.A., Pegram, R.G. and Preston, P.M. (2003) Ticks of Domestic Animals in Africa: A Guide to Identification of Species. Bioscience Reports, Edinburgh.

2. Horak, I.G., Jordaan, A.J., Nel, P.J., van Heerden, J., Heyne, H. and van Dalen, E.M. (2015) Distribution of endemic and introduced tick species in free state Province, South Africa. J. S. Afr. Vet. Assoc., 86(1): 1-9.

3. Mans, B.J., Steinmann, C.M.L., Venter, J.D., Louw, A.I. and Neitz, A.W.H. (2002) Pathogenic mechanisms of sand tampan toxicoses induced by the tick, Ornithodoros savignyi. Toxicon, 40(7): 1007-1016.

4. Adham, F.K., El-Samie-Abd, E.M., Gabre, R.M. and El Hussein, H. (2010) Detection of tick blood parasites in Egypt using PCR assay II- Borrelia burgdorferi sensu lato. J. Egypt. Soc. Parasitol., 40(3): 553-564.

5. Hassan, M.I., Gabr, H.S.M.,Abdel-Shafy, S., Hammad, K.M and Mokhtar, M.M. (2017) Molecular detection of Borrelia sp. In Ornithodoros savignyi and Rhipicephalus annulatus by FlaB gene and Babesia bigemina in $R$. annulatus by $18 \mathrm{~S}$ rRNA gene. J. Egypt. Soc. Parasitol., 47(2): 403-414.

6. Charrel, R.N., Fagbo, S., Moureau, G., Alqahtani, M.H.,
Temmam, S. and De Lamballerie, X. (2007) Alkhurma hemorrhagic fever virus in Ornithodoros savignyi ticks. Emerg. Infect. Dis., 13(1): 153-155.

7. Bouwknegt, C., van Rijn, P.A., Schipper, J.J.M., Hölzel, D., Boonstra, J., Nijhof, A.M., van Rooij, E.M.A. and Jongejan. F. (2010) Potential role of ticks as vectors of bluetongue virus. Exp. Appl. Acarol., 52(2): 183-192.

8. Latip, S.N.H., Nawi, F.W.M. and Mansur, S.H.P. (2017) Potential of selected indigenous plant extracts as botanical pesticides for controlling golden apple snail, Pomacea canaliculata. In: Snails: Biodiversity, Biology and Behavioral Insights. Nova Science Publishers Inc., Hauppauge, New York, p95-116.

9. Walia, S., Saha, S., Tripathi, V., Sharma and K.K. (2017) Phytochemical biopesticides: Some recent developments. Phytochem. Rev., 16(5): 989-1007.

10. Abdel-Shafy, S. and Soliman, M.M.M. (2004) Toxicity of some essential oils on eggs, larvae and females of Boophilus annulatus (Acari: Ixodidae) infesting cattle in Egypt. Acarologia, 44(1-2): 23-30.

11. Abdel-Shafy, S., Soliman, M.M.M. and Habeeb, S.M. (2007) In vitro acaricidal effect of some crude extracts and essential oils of wild plants against certain tick species. Acarologia, 47(1-2): 31-42.

12. Habeeb, S.M., Abdel-Shafy, S. and Youssef, A.A. (2007) Light, scanning electron microscopy and SDS-PAGE studies on the effect of the essential oil, Citrus sinensis var. balady on the embryonic development of camel tick Hyalomma dromedarii (Koch, 1818) (Acari: Ixodidae). Pak. J. Biol. Sci., 10(8): 1151-1160.

13. Abdel-Shafy, S. and Zayed, A.A. (2002) In vitro acaricidal effect of plant extract of neem seed oil (Azadirachta indica) on egg, immature, and adult stages of Hyalomma anatolicum excavatum (Ixodoidea: Ixodidae). Vet. Parasitol., 106(1): 89-96.

14. Massoud, A.M., Kutkat, M.A., Abdel-Shafy, S. and El-Khateeb, R.M. (2005) Acaricidal efficacy of Myrrh (Commiphora molmol) on the fowl tick Argas persicus (Acari: Argasidae). J. Egypt. Soc. Parasitol., 35(2): 667-686.

15. Álvarez, N.M., Ortíz, A.A. and Martínez, O.C. (2016) In vitro antibacterial activity of Curcuma longa (Zingiberaceae) against nosocomial bacteria in Montería, Colombia. Rev. Biol. Trop., 64(3): 1201-1208.

16. Hefnawy, H.T., El-Shourbagy, G.A. and Ramadan, M.F. (2016) Phenolic extracts of carrot, grape leaf and turmeric powder: antioxidant potential and application in biscuits. J. Food Meas. Charact., 10(3): 576-583.

17. Martinez-Correa, H.A., Paula, J.T., Kayano, A.C.A., Queiroga, C.L., Magalhães, P.M., Costa, F.T.M. and Cabral, F.A. (2017) Composition and antimalarial activity of extracts of Curcuma longa L. Obtained by a combination of extraction processes using supercritical $\mathrm{CO}_{2}$, ethanol and water as solvents. J. Supercrit. Fluids, 119(Jan): 122-129.

18. Singh, N., Gupta, S. and Rathore, V. (2017) Comparative antimicrobial study of ethanolic extract of leaf and rhizome of Curcuma longa Linn. Pharmacogn. J., 9(2): 208-212.

19. Sornpet, B., Potha, T., Tragoolpua, Y. and Pringproa, K. (2017) Antiviral activity of five Asian medicinal plant crude extracts against highly pathogenic $\mathrm{H} 5 \mathrm{~N} 1$ avian influenza virus. Asian Pac. J. Trop. Med., 10(9): 871-876.

20. Wu, J., Wang, L., Pan, L., Jia, X.G., Yan, L. and Jiang, Y.Y. (2017) Antifungal activity of 122 kinds of Uighur medicines in vitro. Acad. J. Second Mil. Med. Univ., 38(5): 554-562.

21. Lu, P.S., Inbaraj, B.S. and Chen, B.H. (2018) Determination of oral bioavailability of curcuminoid dispersions and nanoemulsions prepared from Curcuma longa Linnaeus. $J$. Sci. Food Agric., 98(1): 51-63.

22. Al-Zanbagi, N.A. and Zelai, N.T. (2008) Two methods for attenuating Toxoplasma gondii tachyzoites RH strain by using ethanol extract of Curcuma longa. J. Egypt. Soc. Parasitol., 38(3): 965-976. 
23. Pitasawat, B., Choochote, W., Tuetun, B., Tippawangkosol, P., Kanjanapothi, D., Jilpakdi, A. and Riyong, D. (2003) Repellency of aromatic turmeric Curcuma aromatica under laboratory and field conditions. J. Vector. Ecol., 28(2): 234-240.

24. Liu, J., Zhang, M., Fu, W.J., Hu, J.F. and Dai, G.H. (2018) Efficacy of bioactive compounds from Curcuma longa $\mathrm{L}$. against mosquito larvae. J. Appl. Entomol., 142(8): 792-799.

25. Wang, L. and Waller, C.L. (2006) Recent advances in extraction of neutraceuticals from plants. Trends Food Sci. Technol., 17(6): 300-312.

26. Abdel-Shafy, S. (2008) Scanning electron microscopy and comparative morphology of Hyalomma anatolicum excavatum, H. dromedarii and H. marginatum marginatum (Acari: Ixodidae) based on nymphs. Acarologia, 48(1-2): 111-126.

27. Underwood, W., Anthony, R., Cartner, S., Corey, D., Grandin, T., Greenacre, C., Gwaltney-Brant, S., McCrackin, M.A., Meyer, R. and Miller, D. (2013) AVMA Guidelines for the Euthanasia of Animals: 2013 edition. American Veterinary Medical Association, Schaumburg, IL.

28. Bancroft, J.D. and Layton, C. (2013) The hematoxylins and eosin. In: Suvarna, S.K., Layton, C. and Bancroft, J.D., editors. Bancroft's Theory and Practice of Histological Techniques. $7^{\text {th }}$ ed. Churchill Livingstone Elsevier, Oxford. p173-186.

29. Weiss, D.J. and Wardrop, K.J. (2010) Schalm's Veterinary Hematology. $6^{\text {th }}$ ed. Blackwell Publishing Ltd., Ames, Iowa, USA.

30. Reitman, S. and Frankel, S. (1957) A colorimetric method for determination of oxaloacetic transaminase and serum glutamic pyruvic transaminase. Am. J. Clin. Pathol., 28(1): 56-60.

31. Patton, C.J. and Crouch, S.R. (1977) Spectrophotometric and kinetics investigation of the Berthelot reaction for the determination of ammonia. Anal. Chem., 49(3): 464-469.

32. Houot, O. (1985) In: Siest, G., Henny, J., Schiele, F. and Young, D.S., editors. Interpretation of Clinical Laboratory Tests. Biochemical Publications, Foster City, California, USA. p220-234

33. Alamgir, A.N.M. (2017) Herbal drugs: Their collection, preservation, and preparation; evaluation, quality control, and standardization of herbal drugs. Prog. Drug Res., 73: 453-495.

34. Xia, X., Pan, Y., Zhang, W.Y., Cheng, G. and Kong, L.D. (2006) Ethanolic extracts from Curcuma longa attenuates behavioral, immune, and neuroendocrine alterations in a rat chronic mild stress model. Biol. Pharm. Bull., 29(5): 938-944.

35. Chagas, A.C.S., Oliveira, M.C.S., Giglioti, R., Santana, R.C.M., Bizzo, H.R., Gama, P.E. and Chaves, F.C.M. (2016) Efficacy of 11 Brazilian essential oils on lethality of the cattle tick Rhipicephalus (Boophilus) microplus. Ticks Tick Borne Dis., 7(3): 427-432.

36. Choochote, W., Chaiyasit, D., Kanjanapothi, D., Rattanachanpichai, E., Jitpakdi, A., Tuetun, B. and
Pitasawat, B. (2005) Chemical composition and anti-mosquito potential of rhizome extract and volatile oil derived from Curcuma aromatica against Aedes aegypti (Diptera: Culicidae). J. Vector Ecol., 30(2): 302-309.

37. Kemabonta, K.A., Adediran, O.I. and Ajelara, K.O. (2018) The insecticidal efficacy of the extracts of Piper nigrum (Black Pepper) and Curcuma longa (Turmeric) in the control of Anopheles gambiae Giles (Dip., Culicidae). Jordan J. Biol. Sci., 11(2): 195-200.

38. Madhu, S.K. and Vijayan, V.A. (2010) Evaluation of the larvicidal efficacy of extracts from three plants and their synergistic action with propoxur against larvae of the filarial vector Culex quinquefasciatus (Say). Toxicol. Environ. Chem., 92(1): 115-126.

39. Jung, Y.S., Park, S.J., Park, J.H., Jhee, K.H., Lee, I.S. and Yang, S.A. (2012) Effects of ethanol extracts from Zingiber officinale Rosc., Curcuma longa L., and Curcuma aromatica Salisb. On acetylcholinesterase and antioxidant activities as well as GABA contents. J. Korean Soc. Food Sci. Nutr., 41(10): 1395-1401.

40. Chaaban, A., Richardi, V.S., Carrer, A.R., Brum, J.S., Cipriano, R.R., Martins, C.E.N., Silva, M.A.N., Deschamps, C. and Molento, M.B. (2019) Insecticide activity of Curcuma longa (leaves) essential oil and its major compound $\alpha$-phellandrene against Lucilia cuprina larvae (Diptera: Calliphoridae): Histological and ultrastructural biomarkers assessment. Pestic. Biochem. Physiol., 1530(Jan): 17-27.

41. Ozaki, M., Fuchinoue, S., Teraoka, S. and Ota, K. (1995) The in vivo cytoprotection of ascorbic acid against ischemia/reoxygenation injury of rat liver. Arch. Biochem. Biophys., 318(2): 439-445.

42. Sambaiah, K., Ratankumar, S., Kamanna, V.S., Satyanarayana, M.N. and Rao, M.V.L. (1982) Influence of turmeric and curcumin on growth, blood constituents and serum enzymes in rats. J. Food Sci. Technol., 19(5): 187-190.

43. Mesa, M.D., Aguilera, C.M., Ramírez-Tortosa, C.L., Ramírez-Tortosa, M.C., Quiles, J.L., Baró, L., Martínez de Victoria, E. and Gil, A. (2003) Oral administration of a turmeric extract inhibits erythrocyte and liver microsome membrane oxidation in rabbits fed with an atherogenic diet. Nutrition, 19(9): 800-804.

44. Dewanto, V., Wu, X., Adom, K. and Liu, R.H. (2002) Thermal processing enhances the nutritional value of tomatoes by increasing total antioxidant activity. J. Agric. Food Chem., 50(10): 3010-3014.

45. Naczk, M. and Shahidi, F. (2004) Extraction and analysis of phenolics in food. J. Chromatogr. A, 1054(1-2): 95-111.

46. Ali, A., Wang, Y.H. and Khan, I.A. (2015) Larvicidal and biting deterrent activity of essential oils of Curcuma longa, ar-turmerone, and curcuminoids against Aedes aegypti and Anopheles quadrimaculatus (Culicidae: Diptera). J. Med. Entomol., 52(5): 979-986. 